\title{
Ocular Manifestations in Rheumatoid Arthritis Patients - A Hospital Based Cross Sectional Study
}

\author{
Nishi Raghu Satmiamma ${ }^{1}$, Sheeba Chellan Shobhana ${ }^{2}$, Jacob Antony ${ }^{3}$, Siji Vincent Swarna Bai ${ }^{4}$ \\ ${ }^{1}$ Department of Ophthalmology, Government Medical College, Kottayam, Kerala, India. ${ }^{2}$ Department of \\ Ophthalmology, Government Medical College, Thiruvananthapuram, Kerala, India. ${ }^{3}$ Department of Medicine, \\ Government Medical College, Kollam, Kerala, India. ${ }^{4}$ Department of Community Medicine, SUTAMS, \\ Thiruvananthapuram, Kerala, India.
}

\section{ABSTRACT}

\section{BACKGROUND}

The prevalence of rheumatoid arthritis (RA) in India is $0.28 \%$ to $0.7 \%, 15-45 \%$ of patients with RA develop ocular manifestations. Ocular disabilities can be reduced with timely interference by an ophthalmologist. Keratoconjunctivitis sicca (Sjogren's syndrome) is the most common ocular association of RA. This study was done to find out various ocular manifestations in rheumatoid arthritis patients.

\section{METHODS}

A cross sectional study was conducted among the patients attending the rheumatology clinic at Government Medical College, Trivandrum. Patients in the age group of 18-60 years were screened and further evaluated at regional institute of ophthalmology, Trivandrum. Screening for RA was done using the American Rheumatism Association criteria. A complete ophthalmic examination was done for those who satisfied the criteria. The various ocular manifestations in RA are described and presented as proportions.

\section{RESULTS}

Ocular manifestation was found in $38 \%$ of total patients attending the rheumatology clinic. There were 54 females (80.5\%) and 13 males (19.4\%). Age group mainly affected were in $46-50 \mathrm{yr}$ (17.9\%). The duration of rheumatoid arthritis ranged from few months to 25 years. Keratoconjunctivitis sicca was the commonest manifestation found, detected in $22(84 \%)$ patients, episcleritis was noted in two patients $(7.6 \%)$, scleritis in 1 patient $(3.8 \%)$ and marginal furrowing in 1 patient (3.8\%).

\section{CONCLUSIONS}

In this clinic-based study there was a high proportion (38\%) of ocular involvement in RA and hence it is essential to include ophthalmic evaluation as a routine in RA patients. The most common manifestation was keratoconjunctivitis sicca followed by episcleritis, diffuse anterior scleritis and marginal corneal furrowing.

\section{KEY WORDS}

Rheumatoid Arthritis, Keratoconjunctivitis Sicca, Ocular Manifestations, Scleritis, Episcleritis
Corresponding Author: Dr. Nishi Raghu Satmiamma, Department of Ophthalmology, Government Medical College, Kottayam, Kerala, India. E-mail:drnishi.rs@gmail.com

DOI: $10.14260 /$ jemds/2022/26

How to Cite This Article:

Satmiamma NR, Shobhana SC, Antony J, et al. Ocular manifestations in rheumatoid arthritis patients - a hospital based cross sectional study. J Evolution Med Dent Sci 2022;11(01):136-140, DOI: 10.14260/jemds/2022/26

Submission 26-10-2021, Peer Review 12-01-2022, Acceptance 18-01-2022, Published 28-01-2022.

Copyright (C) 2022 JEMDS. This is an open access article distributed under Creative Commons Attribution License [Attribution 4.0 International (CC BY 4.0)] 


\section{BACKGROUND}

Rheumatoid arthritis is mainly characterized by inflammation of the lining, or synovium, of the joints. It can lead to longterm joint damage, resulting in chronic pain, loss of function and disability. RA has a worldwide prevalence of $1 \%{ }^{1,2,3}$ The average age of onset is in the fourth to fifth decade of life, ${ }^{4}$ with a three times greater predilection in women than in men. ${ }^{5}$ It can have devastating systemic and ocular effects. The diagnosis of the disease is made on the basis of clinical criteria (ACR).

$15-45 \%$ of patients with RA develop ocular manifestations. 2,3,6 These include

Episcleritis - Episcleritis

Simple

Nodular

Episcleral Nodules

Sclera $\quad$ - Anterior Scleritis

Non necrotizing - Nodular/Diffuse

Necrotizing with inflammation

Necrotizing without inflammation

(Scleromalacia perforans)

Posterior scleritis

Cornea $\quad-\quad$ Keratoconjunctivitis sicca (KCS)

Sclerosing keratitis

Acute stromal keratitis

Limbal guttering

Keratolysis

Peripheral ulcerative keratitis

Bank keratopathy

Cornea verticellata

(Secondary to NSAIDS or chloroquine)

Peripheral corneal infiltrates

(Secondary to gold compounds)

Lens

- $\quad$ Cataract formation

Lens deposits

(Secondary to gold compounds)

Choroid - Choroidal effusion

Ciliochoroidal detachment

Retina - $\quad$ Exudative retinal detachment

(Secondary to posterior scleritis)

Retinal microangiopathy and infarction

Bull's eye maculopathy

(Secondary to chloroquine)

Extra Ocular Muscles - Extra ocular muscle palsies

Brown's syndrome

Miscellaneous - Blepharoconjunctivitis

Glaucoma ocular disabilities can be reduced with timely interference by an ophthalmologist. The present study is undertaken to describe the various ocular manifestations and their incidence. Keratoconjunctivitis Sicca (Sjogren's syndrome) is the most common ocular association of RA.7,8,9 It is clinically evident in $20-50 \%$ of patients with RA, particularly in women (90\%). It may be an early or presenting manifestation of RA. KCS appears in RA as a result of decreased secretion of tears from the main and accessory lacrimal glands. Histopathologic examination of lacrimal and salivary glands in Sjogren's syndrome reveals infiltration and replacement of normal lacrimal and salivary glandular structures by lymphocytes causing atrophic and cirrhotic changes in the lacrimal glands and reduction in the middle layer of the precorneal tear film. Patients complain of foreign body sensation, burning, itching, excessive mucus production, and a sensation of dryness or paradoxical tearing, all of which intensify in dry and smoky environment. The typical signs observable on evaluation includes a diminished marginal tear strip, superficial punctuate keratopathy (SPK), and ocular surface epitheliopathy; Rose Bengal staining generally reveals a horizontally oriented diamond pattern in the interpalpebral fissure. The consequence of the dryness is epithelial keratopathy most often seen in the interpalpebral fissure where fine epithelial erosions develop that stain with fluorescein. In KCS conjunctival goblet cells are stimulated to increase secretion of mucus, filamentous keratitis, in which a dialysis of corneal epithelium in the form of twisted filaments tied up to the cornea by one part with coverings of mucin is a particularly painful condition because blinking moves the filaments, tugging of the epithelial attachments and tending to strip off further epithelium. It is not clear whether the mucus manifestations are the result of simply an increase in mucus secretion (or an abnormal mucus), or to mucus precipitation because of the disturbed balance of components in the tear. KCS may progress to stromal ulceration, and corneal perforation. After KCS, scleritis is the most common ocular manifestation of RA. ${ }^{10}$ Although it may be an initial sign of rheumatoid disease it typically presents many years after the onset of RA and often at the time when joint inflammation is in remission. Scleral inflammation in RA may extend to adjacent structures and may cause keratitis, anterior uveitis, glaucoma, cataract, retinal, choroidal and optic nerve changes and motility disturbance. Patients with rheumatoid scleritis have more advanced joint disease and more extraarticular manifestations than do rheumatoid patients without scleritis. The occurrence of scleritis is often a harbinger of worsening systemic disease and warrants reevaluations of the existing medical therapy in these patients. The 3 year mortality rate of patients with scleritis associated with RA is 36 to $45 \%$, if not aggressively treated with immunosuppressive therapy.

Simple episcleritis is more common in patients with RA. The presence of subconjunctival nodules that are mobile over the sclera differentiates nodular episcleritis from simple episcleritis. The episcleritis in the RA patients was relatively mild in all instances with an incidence of $0.17 \%$ in RA. Patients usually complain of hot, prickly or foreign body like sensation. Tenderness may be present localized to the inflamed area. Unlike typical idiopathic episcleritis, it did generally require the use of a systemic NSAID for resolution.

Corneal lesions- Corneal disease in patients with RA can be an isolated complication but it is most commonly associated with keratoconjunctivitis sicca or a form of anterior scleritis. The spectrum of disease may include keratitis, sclerosing keratitis, and peripheral or paracentral ulcerative keratitis. The drying effects of keratoconjunctivitis sicca leads to devitalized epithelial cells and punctuate epithelial erosion. Acute keratitis has been identified in 30 to 70 percent of patients with scleritis or episcleritis associated RA. Keratitis associated with scleritis may be acute (acute stromal keratitis and keratolysis) or sclerosing. It is marked by an inflammatory cell infiltrate that may result in corneal scarring, ulceration, or melting. It may occur as an isolated 
finding, following previous episode of scleritis even in the setting of previous successful scleritis treatment with immunosuppressive agent. Acute stromal keratitis can manifest as stromal opacities at any level in the cornea with companying stromal oedema. The opacities may coalesce if left untreated. Overlaying epithelium may breakdown with the development of peripheral ulcerative keratitis. Vascularization and thinning of the cornea may occur as well. Many of these findings may resolve with appropriate treatment and resolution of accompanying scleritis.

Peripheral corneal ulceration is potentially devastating disorder consisting of a crescent shaped destructive inflammation at the margin of corneal stroma that is associated with an epithelial defect, presence of stromal inflammatory cells, and progressive stromal degradation and thinning. It may occur in association with necrotizing scleritis in inflamed or noninflamed eyes. Loss of stroma occurs in regions of clear cornea and may progress to descemetocele formation. Corneal and scleral stromal lysis with wound dehiscence has been described after cataract and strabismus surgery in patients with RA, often in patients with preoperative KCS. Rarely, cryoglobulins (complexes of RF and polyclonal IgG that precipitate at temperatures lower than 370C [98.60F] precipitate in the peri limbic circulation, leading to ulcers that can perforate the cornea with extrusion of the aqueous. Anterior uveitis accompanying episcleritis or scleritis is a common finding in RA but anterior uveitis alone probably has no higher incidence in adult RA patient than in general population.

We wanted to find out various ocular manifestations in rheumatoid arthritis.

\section{METHODS}

A cross -sectional study was conducted at the Rheumatology Clinic of Trivandrum Medical College during August 2005April 2007. Diagnosis of rheumatoid arthritis was based on the 1988 Revised American Rheumatism Association Criteria. ${ }^{10} 67$ patients in the age group of 18-60 yrs were included in the study as per the criteria. All patients were subjected to a detailed examination, which included history taking as to, age, the duration of disease, treatment taken, other systemic illness and ocular complaints.

A detailed ocular examination was done using torch light and slit lamp. Detailed fundus examination was done to rule out maculopathy and any evidence of vasculitis using direct ophthalmoscope, $90 \mathrm{D}$ and indirect ophthalmoscope. Lacrimal secretion was measured using Schirmer's test I and II using Whatmann filter paper No. 41. Lissamine green staining \& TBUT was done in these cases. ${ }^{11,12,13,14}$ Macular function was assessed using colour vision and Amsler's grid test. FFA, field analysis and B-Scan were ordered if necessary. RA patients when tested positive for above mentioned tests were considered as having ocular manifestations. Patients with ocular manifestations were given the standard treatment available. Ethical committee clearance was obtained from the Institution. Written informed consent was obtained from all the study participants.

\section{Statistical Analysis}

The data was coded, entered and analysed in MS Excel 4.0. The quantitative variables were expressed as mean and standard deviation. The qualitative variables were analysed and represented as proportion.

\section{RESULTS}

67 diagnosed rheumatoid arthritis patients were included in the study. The mean age of the study participants was 42.8 yrs, 46-50 yrs age group (17.9\%) was the predominant group. Majority of the patients were females (80.59\%).61.2\% of the patients had ocular manifestations and $84 \%$ had keratoconjunctivitis sicca, followed by episcleritis $7.6 \%$. Scleritis and marginal furrowing were less common with $3.8 \%$.

\begin{tabular}{|cc|}
\hline Patients & $\begin{array}{r}\text { Number (percentage) } \\
\text { Total N=67 (100\%) }\end{array}$ \\
Males & $13(19 \%)$ \\
Females & $54(80.59 \%)$ \\
\hline Table 1. Gender Distribution of Study Participants \\
\hline
\end{tabular}

\begin{tabular}{|cc|}
\hline Age Groups (yrs) & $\begin{array}{c}\text { Number (percentage) } \\
\text { Total N=67 (100\%) }\end{array}$ \\
$21-25$ & $5(7.5 \%)$ \\
$26-30$ & $5(7.5 \%)$ \\
$30-35$ & $7(10.4 \%)$ \\
$36-40$ & $11(16.4 \%)$ \\
$41-45$ & $8(11.9 \%)$ \\
$46-50$ & $12(17.9 \%)$ \\
$51-55$ & $9(13.4 \%)$ \\
$56-60$ & $7(10.4 \%)$ \\
$61-65$ & $2(2.9 \%)$ \\
$66-70$ & $1(1.5 \%)$ \\
\hline Table 2. Age Distribution of Study Participants \\
\hline
\end{tabular}

\begin{tabular}{|cc|}
\hline Duration (yrs) & $\begin{array}{c}\text { Number (percentage) } \\
\text { Total N=67 (100\%) }\end{array}$ \\
$0-5$ & $43(64.2 \%)$ \\
$6-10$ & $16(23.9 \%)$ \\
$11-15$ & $4(5.9 \%)$ \\
$16-20$ & $2(2.9 \%)$ \\
$21-25$ & $2(2.9 \%)$ \\
\hline Table 3. Distribution of Study Participants Based on Duration of \\
Rheumatoid Arthritis \\
\hline
\end{tabular}

\begin{tabular}{|cc|}
\hline & $\begin{array}{c}\text { Number (percentage) } \\
\text { Total N=67 (100\%) }\end{array}$ \\
\hline $\begin{array}{c}\text { No. of patients having ocular manifestations } \\
\text { No. of patients not having ocular manifestation }\end{array}$ & $26(38.8 \%)$ \\
\hline \multicolumn{2}{|c|}{ Table 4. Distribution of Study Participants Based on Ocular } \\
Manifestations
\end{tabular}

\begin{tabular}{|cc|}
\hline Ocular Manifestations & $\begin{array}{r}\text { Number (percentage) } \\
\mathbf{N}=\mathbf{2 6}(\mathbf{1 0 0} \%)\end{array}$ \\
Marginal furrowing & $1(3.8 \%)$ \\
Scleritis & $1(3.8 \%)$ \\
Episcleritis & $2(7.6 \%)$ \\
KCS & $22(84 \%)$ \\
\hline Table 5. Distribution of Ocular Manifestations \\
\hline
\end{tabular}

\section{DISCUSSION}

A total of 67 rheumatoid arthritis patients attending the clinic were studied. There were $54(80.59 \%)$ females and 13 $(19.4 \%)$ males. Female: male ratio was $4.15: 1$. Similar female 
predominance was noted in other studies also like Chandreskharan et al. ${ }^{15}$ (4:1) and Narayanan et al. ${ }^{16}$ (4:1). In this study age group of the study population ranges between 20-80 years with maximum number of patients in the age group of 46-50 years (17.9\%). Mean age group in a study by Wanchu et al. was 41 years and mean age group in the study by Waters et al. was 45 years which showed concordance with the present study. The mean age in the present study was 42.48 years.

In this study population, duration of disease (RA) ranged between few months to 25 years. Mean duration of illness was 5.2 years $64.2 \%$ of patients had disease duration in the range of 0-5 years. Wanchu et al. had studied patients with disease duration of $5.3+4.1$ years. In a study by Kalke et al. the mean duration was 5 years. In this study population, ocular manifestations were found in $(38.8 \%)$ patients in the age group of 46-50 years (17.9\%).

Ocular manifestations detected were keratoconjunctivitis sicca, episcleritis, diffuse anterior scleritis, and peripheral ulcerative keratitis. Comparing the present study with other studies in the table below:

\begin{tabular}{|cc|}
\hline Studies & Ocular Manifestations \\
\hline Mody et al..$^{17}$ & $31.7 \%$ \\
${\text { Reddy SC \& } \text { Rao }^{18}}^{18}$ & $24.40 \%$ \\
Bharodia et al. $^{14}$ & $19.63 \%$ \\
Ashu et al. & $21.81 \%$ \\
Present study & $38 \%$ \\
\hline
\end{tabular}

Keratoconjunctivitis sicca was the commonest manifestation found, detected in (84\%) patients. In a study by Shaw et al. incidence of severe dry eye was $5.55 \%$. While 37.03 had borderline tear deficiency. A few of them had corneal epithelial lesions. All diagnosed patients were put on lubricant eye drops and were followed up. Reddy et al. ${ }^{19}$ has found $29 \%$ of KCS in their study conducted at Hyderabad in India, Gilboe et al..$^{20}$ has found an incidence of $21 \%$, while the study by by Bhadoria et al. ${ }^{21}$ showed an incidence of $17.7 \%$ and the incidence of KCS in the study by Mastuo et al. was ${ }^{22}$ $17.10 \%$. Most of these studies show concordance with our study and in all of them KCS was the commonest ocular manifestation. In the present study episcleritis was noted in two patients (7.6\%). Shaw C et al. reported an incidence of $3.7 \%$ episcleritis in their study. Bharodia et al. had an incidence of $0.93 \%$ in their study.

Diffuse anterior scleritis was seen in 1 patient $(0.03 \%)$. In a study by Matsuo et al. the incidence of scleritis was $0.9 \%$

Marginal corneal furrowing was seen in 1 patient $(0.03 \%)$. Reddy et al. $^{20}$ in this study has reported a case of marginal corneal furrowing.

\begin{tabular}{|ccc|}
\hline Ocular Manifestation & Other Studies & Present Study \\
& $\begin{array}{c}(29 \%) \text { Reddy et al. } \\
(21 \%) \text { Gioboe et al. }\end{array}$ & $84 \%$ \\
KCS & $(17.7 \%)$ Bhadoria et al. & \\
& $(17.10)$ Mastuo et al. & \\
Scleritis & $(0.9 \%)$ Matsuo et al. & $3.8 \%$ \\
Episcleritis & $(3.7 \%)$ Shaw C et al. & $7.6 \%$ \\
PUK & $(0.03 \%)$. Reddy et al. & $3.8 \%$ \\
\hline
\end{tabular}

\section{CONCLUSIONS}

The present study shows that there is a high incidence of ocular involvement in rheumatoid arthritis. Therefore, it is essential to include ophthalmic evaluation as a routine for rheumatoid arthritis patients to facilitate timely diagnosis so that appropriate management strategies can be employed to prevent ocular morbidity as all these patients may not be symptomatic. The most common ocular manifestation detected was keratoconjunctivitis sicca, followed by episcleritis, diffuse anterior scleritis and marginal corneal furrowing.

Data sharing statement provided by the authors is available with the full text of this article at jemds.com.

Financial or other competing interests: None.

Disclosure forms provided by the authors are available with the full text of this article at jemds.com.

\section{REFERENCES}

[1] Gabriel SE. The epidemiology of rheumatoid arthritis. Rheum Des Clin North Am 2001;27(2):269-81.

[2] Alarcon GS. Epidemiology of rheumatoid arthritis. Rheum Dis Clin North Am 1995;21(3):589-604.

[3] Gsbriel SE, Crowson CS, O'Fallan NM. The epidemiology of rheumatoid arthritis in Racheoles, Minnesota 19551985. Arthritis Rheum 1999;42(3):415-20.

[4] Kar N. A short communication on occurrence of rheumatic diseases attending hospital. Indian J Public Health 1994;38(3):115-8.

[5] Del Puente A, Knower WC, Pettitt DJ, et al. High incidence and prevalence of rheumatoid arthritis in pima Indians. Am J Epidemiol 1989;129(6):1170-6.

[6] Williamson J. Incidence of eye disease in cases of connective tissue diseases. Trans Opthalmol Soc UK 1974;94(3):742-52.

[7] Talal N. Sjogren's syndrome: historical overview and clinical spectrum of disease. Rheum Dis Clin North Am 1992;18(3):507-15.

[8] Ericson S, Sundmark E. Studies on the sicca syndrome in patients with rheumatoid arthritis. Scand J Rheumatol 1987;16(1):60-80.

[9] Pflug Fielder SC, Whitcher JP, Daniels T. Sjogren's syndrome. In: Pepose J, Holland G editors: Ocular infection and immunity. New York: Mosby Year Book 1996.

[10] Arnett FC, Edworthy SM, Bloch DA, et al. The American Rheumatism Association 1987 revised criteria for the classification of rheumatoid arthritis. Arthritis Rheum 1988;31(3):315-24.

[11] Bandem-Roche K. Challenges to defining and quantifying dry eye. Invest Ophthalmol Vis Sci 1995;36:S862.

[12] Nelson JD. Diagnosis of kerataconjunctivitis sicca. Int Ophthalmol Clin 1994;34(1):37-56.

[13] Paschider CA, Kitsios G, Karakostas KX, et al. Evaluation of tear break up time, Schirmer's test and rose Bengal staining as confirmatory tests for keratoconjunctivitis sicca. Clin Exp Rheumatol 1989;7(2):155-7.

[14] van Bijsterveld OP. Diagnostic tests in the sicca syndrome. Arch Ophthalmol 1969;82(1):10-4.

[15] Chandrasekaran AN, Radhakrishna B, Pokordi R, Madhavan R, Parthiban M. Spectrum of clinical and immunological features of systemic rheumatic disorders in a referral hospital in South India: rheumatoid arthritis. J Indian Rheum Assoc 1994;2:18-26. 
[16] Narayanan K, Rajendran CP Parkodi K et al. Late onset rheumatoid arthritis a clinical and laboratory study. J assoc physician India 2001;49:311-3.

[17] Albeach KA, Lauer M, Stolze HH. Diagnosis of keratoconjunctivitis sicca in rheumatoid arthritis. The value of various tests. Ophthalmologe 1994;91(2):22934.

[18] Mody GM, Hill JC, Myres OL. Kertoconjunctivities sicca in rheumatoid arthritis. Clin Rheumatol 1988;7(2):237-41.

[19] Reddy SC, Rao UR. Ocular complication of adult rheumatoid arthritis. Rheumatol Int 1996;16(2):49-52.
[20] Gilboe IM, Kvien TK, Uhlig T, et al. Sicca symptoms and secondary Sjögren's syndrome in systemic lupus erythematosus: comparison with rheumatoid arthritis and correlation with disease variables. Ann Rheum Dis 2001;60(12):1003-9.

[21] Bharodia DP, Bhadoria P, Sundaram KR, et al. Ocular manifestations of rheumatoid arthritis. J Indian Med Assoc 1989;87(6):134-5.

[22] Matsuo T, Kono R, Matsuo N, et al. Incidence of ocular complications in rheumatoid arthritis and the relation of keratoconjunctivitis sicca with its systemic activity. Scand J Rheumatol 1997;26(2):113-6. 